\title{
HEMOPHILIA IN CHILDREN
}

\author{
S ISLAM ${ }^{1}$, AKMA MORSHED $^{2}$, ZJ KHAN ${ }^{3}$
}

\begin{abstract}
Hemophilia is the most common serious congenital coagulation factor deficiencies. The prevalence of hemophilia is estimated to be about $1: 10,000$ birth and that of the severe form of the disease to be about $6 \%$ per $1,00,000$ population. The most pathetic part of this disease is that even medical personnel are sometimes not familiar with its diagnosis and management. There is obviously a need to establish facilities and treatment options that will help the patient with hemophilia to manage their life with ease. As this is a genetic disorder no complete cure is possible as of now. The only available treatment option is the infusion of factors and some adjuvant therapies depending upon the bleeding conditions .Hemophilia, if not properly managed, can lead to chronic disease and lifelong disabilities. The challenges and issues in infants/young children are different from those in older children and adults although episodes of bleeding still predominate as the diagnostic trigger. Currently, inhibitor development is a challenging complication of pediatric hemophilia and prophylaxis is emerging as the optimal preventive care strategy. In this section we will review some important aspects of hemophilia in children including early prophylaxis, current evidence relating to inhibitor development.
\end{abstract}

Keywords: Hemophilia, Children, Clotting factor, Inhibitors, Prophylaxis, Comprehensive care.

\section{Introduction:}

The hemophiliacs are the commonest inherited bleeding disorder which can lead to chronic

1. Dr. Shahnoor Islam, Associate Professor, Department of Pediatric Surgery, Dhaka Medical College Hospital. Dhaka1000,Bangladesh

2. Dr. AKM Amirul Morshed, Associate Professor and Head, Department of Pediatric Hematology and Oncology, Dhaka Medical College Hospital. Dhaka-1000,Bangladesh

3. Dr. Zohora Jameela Khan, Associate Professor, Department of Pediatric Hematology and Oncology, Dhaka Medical College Hospital. Dhaka-1000,Bangladesh.

Correspondence to: Dr. Shahnoor Islam, Associate Professor, Department of Pediatric Surgery, Dhaka Medical College Hospital, Dhaka-1000, Bangladesh. E-mail: shahnoor6989@yahoo.com. disorder and lifelong disabilities if not properly managed $^{1}$. Hemophilia A (deficiency in factor $[F]$ VIII) and hemophilia B (deficiency in FIX) are the most common serious congenital coagulation factor deficiencies. Hemophilia A is more common, occurring in 1:5000 male births, whereas hemophilia B occurs in 1:30,000 male births. Hemophilia is found in all ethnic groups; there is no geographic or racial predilection. Although easy bruising and excessive mucosal bleeding may be the first signs of hemophilia, severe soft tissue bleeding and hemarthroses are the classic bleeding symptoms. Because there are 3 subtypes (which are different in both severity and heredity), clinical symptoms vary from mild mucosal bleeding to hemarthroses.2,3. Understanding of the pathphysiology has long been delayed due to complexity of clotting mechanism. Due to advancement in protein chemistry and recombinant DNA technology a comprehensive account of normal coagulation and molecular genetics of hemophilia have been explored. Hemophilia is likely to be first common severe genetic disorder to be cured by gene therapy until then main challenge remains to overcome the development of inhibitor and managing patient with inhibitors and in fact it is also a great challenge for the society to provide proper management to four fifth of hemophilia, who are living in developing countries ${ }^{4}$.

Hemophiliacs are the hereditary bleeding disorder due to absence or deficiency of plasma clotting factors, resulting in prolong and uncontrolled bleeding either spontaneously or following trauma ${ }^{5}$. Two most common forms of hemophilia are Hemophilia A (HA) and Hemophilia $B(\mathrm{HB})$ and are caused by deficiency 
of factors VIII and IX respectively. HA accounts for $80-85 \%$ of cases and HB in $15-20 \%$ of cases ${ }^{5,} 6$. Both types are inherited as $X$ linked recessive pattern characterized by prolonged bleeding and hemorrhages typically in joints and soft tissues ${ }^{7}$. An uncommon type, Hemophilia $C$ is an autosomal recessive defect that results in deficiency of factors XI.

\section{Epidemiology:}

Hemophilia is prevalent worldwide and occurs in all racial and socioeconomic groups ${ }^{7}$. The incidence of HA and HB is about 15-20 per 100000 male born worldwide. $\mathrm{HA}$ is also known as 'Classical hemophilia 'and occurs 1 in 10,000 male births ${ }^{6}$. HB also known as 'Christmas disease' occurs in about 1 in 25,000 male births. According to the Report of the annual global survey 2014, by World federation of Hemophilia (WFH) with a participating 106 countries, total number of hemophiliac is 178500 of which 143523 is HA and 24,038 is HB9. Number of HA and HB patients with clinically identified inhibitors was $5013 \& 363^{4}$. However, these figures are an underestimate than actual ones. Because as per estimation of WFH, with a prevalence of $\mathrm{HA}$ and $\mathrm{HB}$ of 135 per million male child (world population being 6 billion), there would have been 399,000 hemophilia worldwide. So majority of the patients remains under diagnosed and it is true that most of them are living in the developing countries ${ }^{8}$.

\section{Genetics:}

$\mathrm{HA}$ and $\mathrm{HB}$ are transmitted by $X$ linked recessive fashion. Genes for HA and HB are located on tip of the long arm of $X$ chromosomes in band Xq28 \& Xq27 respectively ${ }^{1}$. So there is $50 \%$ chance that son of a female carrier will inherit the disorder. Male with hemophilia will not transmit this disease to his son but all his daughters will be carrier.. HA can result from many genetic errors like a large variety of point mutation, gene deletion, stop codon abnormality, frame shift mutation and inversion mutation. These knowledge help in carrier identification by DNA analysis and correction of gene defect to prevent inhibitor development ${ }^{9}$.

Early studies identified genetic defect in nearly all patients who had mild to moderate hemophilia but only $50 \%$ of cases of severe hemophilia. Recent works showed that a novel "FLIP TIP" inversion at the end of $X$ chromosome is responsible for the $50 \%$ cases of hemophilia. Here, a small gene of unknown mutation termed F8A is inserted within a non coding region of large FVIII resulting division and inactivation of FVIII gene. This mutation facilitates testing DNA for carrier identification ${ }^{9}$.

\section{Hemostasis and the role of factor VIII and IX:}

Bleeding occurs in hemophilia due to failure of secondary hemostasis. Primary hemostasis is the formation of the platelet plug that occurs normally but the stabilization of the fibrin is defective because inadequate amount of fibrin are generated. Factor VIII and IX are known to be central to the process of blood coagulation and for the adequate generation of thrombin ${ }^{2}$.

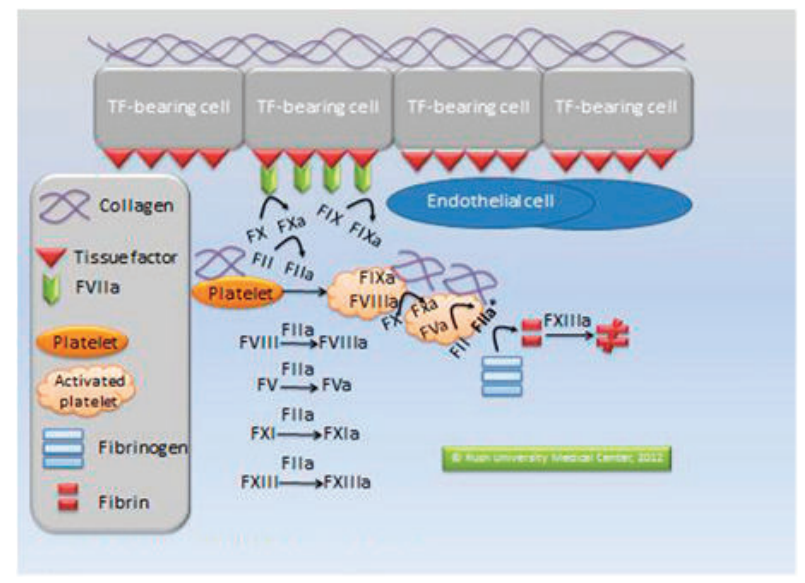

Fig.-1: Cell-based model of blood coagulation. F[factor]; TF[tissue factor]

\section{Clinical manifestation:}

Hemophilia A and B are difficult to distinguish from a clinical point of view. Replacement of hemostatic concentrations of the deficient factor is the mainstay of treatment for bleeding episodes, according to the type and severity of bleeds and until complete resolution of symptoms Recurrent joint bleeds, inevitably leading to hemarthosis ${ }^{10}$.

$\mathrm{HB}$ is relatively milder disease so often diagnosed relatively in later life. Hemophiliacs have the heterogeneous phenotypic presentation depending upon its severity described in the table $\mathrm{I}^{11}$. 
Table I

Relationship of factor level to the severity of clinical presentation in hemophilia

\begin{tabular}{lcl}
\hline Types & $\%$ of FVIII \& FIX & Type of hemorrhage \\
\hline Severe & $<1$ & Spontaneous; hemarthroses and deep tissue hemorrhages \\
Moderate & $1-5$ & $\begin{array}{l}\text { Gross bleeding following mild to moderate trauma some } \\
\text { Hemarthroses; seldom spontaneous hemorrhages }\end{array}$ \\
Mild & $>5-<40$ & $\begin{array}{l}\text { Severe hemorrhages only following moderate to severe } \\
\text { trauma,Spontaneous bleeding is rare }\end{array}$ \\
\hline
\end{tabular}

Table-II

Common sites of hemorrhage in hemophilia ${ }^{11}$.

Hemarthrosis
Intramuscular hematoma hematuria
Mucous membrane hemorrhage:
Mouth
Dental
Epistaxis

\section{High risk hemorrhage}

Central nervous system Intracranial extracranial

Severe hemophilia usually present in neonatal period and early infancy, while moderate hemophilia in toddlers and mild hemophilia in late childhood or adolescent and adult often incidental or following major trauma ${ }^{13}$. Bleeding is the hallmark of hemophilia, sites and pattern of bleeding varies over life time ${ }^{8}$..

Table-III

Sites of bleeding episodes in 278 newborn with hemophilia $^{12}$

\begin{tabular}{lcc}
\hline Sites of bleeding & Frequency & Percentage \\
\hline Circumcision & 126 & 45.49 \\
Head (ICH) & $49(16)$ & $17.69(32.6)$ \\
Heal stick & 41 & 14.8 \\
Venepuncture & 10 & 3.6 \\
Intramuscular injection & 9 & \\
3.25 & & \\
Soft tissue & 7 & 2.53 \\
Oral mucosa & 3 & 1.08 \\
Joint & 1 & 0.36 \\
Others & 22 & 7.94 \\
Unknown & 9 & 3.25 \\
\hline
\end{tabular}

Children and adolescent: Hemarthrosis is the leading bleeding symptoms in older children and adolescent. Recurrent bleedings causes pathological changes leading to 'target joint' and eventually further bleeding into the joint occur without trauma, overtime this cycle of bleeding causes erosion of joint cartilage resulting in arthritis and the crippling deformities of hemophilic arthropathy ${ }^{14}$. Radiological joint damage might appear by 6 years in subjects with no or minimal episode of hemarthrosis ${ }^{2}$. Eighty percent of bleeding occurs in knee, ankles, and elbow; however involvement of other joints is not unusual. Karim et al in their study in Bangladeshi children shows $82 \%$ children present with joint symptoms and knee joint involvement was the most common (68\%) followed by ankle joint (44\%) and elbow joint (14\%) 15 . Hemarthrosis as the predominant presentation with most affected joint being knee joints were also found in Korean study ${ }^{15}$ However many other studies conducted in Netherlands, France and Spain showed ankle joint as mostly affected joints. Muscular bleeding occurs in $10-25 \%$ of all bleeds in severe hemophilia and bleeding may become limb threatening, recovery and rehabilitation may be protracted ${ }^{16}$. In contrast to hemarthrosis, muscle bleeds are mostly associated with trauma ${ }^{25}$. Affected muscles become swollen, painful and stiff. There may be bruising on overlying skin if the bleeding occurs in superficial muscle. Deeper muscle bleeding causes pressure on nerves leading to numbness and tingling sensation and if not properly treated by factor replacement leads to compartmental syndrome ${ }^{5}$

Intracranial hemorrhage is the serious complication of hemophilia with a significant cause of disability and long term neurological sequelae as many as 60$75 \%$ cases ". Prevalence of symptomatic $\mathrm{ICH}$ in all ages varies from $3-12 \%$ with a substantial proportion occurring in children Hematuria: Hematuria usually 
results from blow to the flank, renal calculi and rarely, it may be spontaneous and asymptomatic. It is an infrequent occurrence before 12 years of age. Every patient with haemophilia will present at least one episode of haematuria in his lifetime. There is a greater incidence in spring and autumn. In general, haematuria episodes have a short duration and do not cause any severe sequelae, except in patients with high titer inhibitors and in HIV patients with bone marrow hypoplasia ${ }^{16}$.

\section{Diagnosis of hemophilia:}

Arrangement of collection of blood sample from fetal side of placenta should be done if there is possible family history or mother of a male fetus is known or possible carrier. If any newborn /child presents with unusual / prolonged bleeding is subjected for basic screening test.

Screening tests: Complete blood count remains normal other than anemia. Bleeding time: remains normal. Prothrombin time (PT): also normal in hemophilia. Activated partial thromboplastin time (APTT): usually increased by one and half fold to more than 2 fold. Normal hemogram, bleeding time and PT with prolonged APTT leads to the suspicion of hemophilia which warrants specific factor analysis ${ }^{2}$

Specific study: Correction study with deficient plasma might identify the types of hemophilia and with normal plasma might suggest presence of inhibitors. Quantitative assay of FVIII, FIX helps in identify the types of hemophilia and its severity. Molecular genetic testing: $a$. Sequence analysis, $b$. Targeted sequence analysis, c. Deletion and duplication analysis and Linkage analysis for a) Tracking an unidentified mutation, b) Identifying the origin of de novo mutation.

Carrier detection: a) Factor assay- usually lower than normal b) DNA analysis- identifies the genetic abnormality.Antenatal diagnosis: by collecting sample of chorionic villous (CVS) in 10-12 weeks of pregnancy and amniotic fluid (amniocentesis) in 16-20 weeks of pregnancy for molecular genetic testing ${ }^{17}$.

\section{Management of hemophilia:}

Hemophilia is managed through a combination of education, clotting factor replacement and comprehensive care. Proper exercise and nutrition help control bleeding and maintain health.

Primary aims are- prevention of bleeding and treatment of acute bleeding,Provide comprehensive care by multidisciplinary care team, Home therapy, Attention for psychosocial health and Rehabilitation ${ }^{18}$.

Treatment of acute bleeding: Factor replacement and other pharmaceutical therapy.
Factor replacement: Replacement therapy is the breakthrough in the treatment of hemophilia which started with fractionated human plasma (FFP) in 1930 's ${ }^{19}$ which reduces mortality. Cryoprecipitate, first available in 1960's provide concentrated FVIII (100 unit in $5-15 \mathrm{ml}$ bag). It is also in use in many countries because of its availability and low cost. Unfortunately both the FFP and cryoprecipitate are not heat treated and not recommended for specific therapy as they contain many other factors and they must be kept frozen until use ${ }^{19}$. FVIII and FIX concentrate developed during1960's and 1970's, by additional purification technique, provides specific replacement therapy for specific hemophilia. Recombinant factor VIII developed in 1984 through sequencing of human factor VIII gene but Only disadvantage is its high cost.

\section{Principles for factor replacement ${ }^{18}$}

- Factor replacement in acute bleeding should be prompt and within 2 hours and if in doubt about the bleeding treatment should be started before assessment is complete.

- Whenever possible specific deficiency should be corrected by specific factors

- Adjuvant therapy can be used to control bleeding in the absence of clotting factor concentrate

- If bleeding does not resolve despite adequate treatment, clotting factor should be assayed and inhibitors should be assayed if the clotting factors level are unexpectedly low.

- Home therapy can be encouraged in case of mild to moderate bleeding.

Table-IV

Facts regarding factor replacement are shown in table IV5

\begin{tabular}{lcc}
\hline Facts & FVIII & FIX \\
\hline $\begin{array}{l}\text { Normal level of activity (\%) } \\
\text { Rise of factor level by infusion }\end{array}$ & $2 \%$ & $1 \%$ \\
$\begin{array}{l}\text { of } 1 \text { unit } \\
\text { Half life }\end{array}$ & $50-100 \%$ \\
hours & $8-12$ hours & $18-24$ \\
$\begin{array}{l}\text { Haemostatic level } \\
\text { Mild to moderate hemorrhage }\end{array}$ & $30-50 \%$ & $25-30 \%$ \\
$\begin{array}{l}\text { Severe life threatening } \\
\text { hemorrhage }\end{array}$ & $100 \%$ & $100 \%$ \\
\hline
\end{tabular}

Calculation of dose of recombinant FVIII and FIX is as follows 13; Dose of FVIII= \% desired of factor $\times$ Body weight $(\mathrm{kg}) \times 0.5$, Dose of $\mathrm{FIX}=\%$ desired of factor $\times$ Body weight $(\mathrm{kg}) \times 1.4$ 


\section{Table-V}

Types of products currently in use for replacement are shown in table- $V^{20}$

\section{Hemophilia A}

High purity plasma derived FVIII concentrates

Full length recombinant FVIII concentrates

b domain deleted recombinant FVIII concentrates

\section{Hemophilia B:}

High purity plasma derived FIX concentrates

Recombinant IX concentrates

For effective treatment factor level should be raised to haemostatic level depending upon types of bleeding and should be maintained satisfactorily for a sufficient period of time. However WFH also recommended factor replacement schedule when there is significant resource constraint ${ }^{22}$.

Other pharmaceutical option for treatment of bleeding:

Desmopressin .Tranexamic acid, Epsilon aminocaproic acid are some alternate option of limited benift.

\section{Surgical management:}

Surgery should be performed in person with hemophilia in a well organized hemophilia care setting with appropriate communication and planning between the medical staffs, surgeons and coagulation technologists. The patient's inhibitor status must be known before hand. Whenever possible, initial bolus dose of desired clotting factors should be followed by continuous infusion of factors. This will prevent hazardously low trough level of clotting factors caused by delay in infusion of follow up doses. ${ }^{22}$.

Management of inhibitors: Inhibitors are the alloantibodies develop against infused coagulation

factors occurring mainly in severe hemophilia and commonly in hemophilia A11. Inhibitor development is the most significant complication and remains the biggest challenge in hemophilia care today ${ }^{21}$.Antibodies inactivates the pro coagulant activities of FVIII ${ }^{5}$, and inhibits patients response to replacement

Incidence of inhibitors development is approximately $30 \%$ in hemophilia A and 3\% in hemophilia B and inhibitors tends to develops early in the course of replacement therapy and develops relatively early in childhood and within 50 exposure to FVIII (median 10-11 exposures) .Debates continue on risk of development of inhibitors. Severity of the disease, genetic factor, family history, non Caucasian is the major risk factors for inhibitor development. Gene deletion, frame shift mutations are the genetic defects plays major role. Inhibitors should be suspected in any patient who fails to respond clinically to clotting factors, particularly if he has been previously responsive. In this situation, the expected recovery and half-life of the transfused clotting factor are severely diminished and these patients must be subjected for detection of inhibitor. Inhibitors are quantitated using the Bethesda assay and clinically are classified as Low responder $<5$ Bethesda unit (BU) or high responder e" 5BU5,13. Very low level of $0.08 \mathrm{BU}$ can be detected by using Nijmegen modification of Bethesda methods ${ }^{23}$.

Low responder inhibitors: Approximately half of patients with inhibitors are low responders and, of these, approximately half will have transient inhibitors. These patients do not exhibit anamnesis upon repeated exposure to FVIII; 1 BU neutralizes $50 \%$ of factor VIII/IX activity. In patient with very low titer inhibitors generally treated with a higher dose of FVIII results in disappearance of inhibitors in some cases, other remains with low titer while other cases becomes high titer inhibitor overtime ${ }^{4}$.

High responder inhibitors: Treatment of an acute bleeding by the use of bypassing agents (activated prothrombin complex concentrate [aPCC] and recombinant FVIIa [rVIIa]) and inhibitor eradication is achieved through immune tolerance.

Life-threatening bleeding: If the inhibitor titer is $<20$ $B U$ : High-dose continuous infusion of FVIII with the adjustment of dose based on recovery and survival studies. If a factor VIII level is not attainable or the antibody level is greater than $20 \mathrm{BU}$ : By-passing agents to initiate hemostasis independent of FVIII, such as treatment with activated prothrombin complex concentrates (aPCC) or rFVIla. There is no demonstrated difference in the efficacy of either product.

Immune tolerance induction (ITI): The goal of ITI is the permanent eradication of inhibitors with restoration of normal pharmacokinetics defined as plasma FVIII recovery $>66 \%$ and a half life $>6$ hours determined following a 72 hours FVIII exposure free period. Mechanism of ITI and the best means to achieve tolerance still unknown, despite development of multiple ITI protocol since its inception in the 1970's.

Prophylactic therapy: Prophylactic therapy is the regular infusion of exogenous coagulation factors in a person with hemophilia in order to prevent spontaneous bleeding. Prophylactic infusion of factor concentrate of FVIII and FIX is widely accepted as gold standard treatment in children with severe hemophilia. Prophylaxis prevents bleeding and joint destruction and should be the goal to preserve normal musculoskeletal function. The aim of prophylaxis is to convert the severe hemophilia to a milder form by maintaining the trough level of factors essentially $>1 \%$ of normal ${ }^{20}$. . 
Table-VI

Immune tolerance protocol

\begin{tabular}{|c|c|c|}
\hline Bonn protocol & Malmo protocol & Van Creveld \\
\hline fVIII 100 U/kg BID & $\begin{array}{l}\text { Immunoadsorption using protein A column } \\
\text { if inhibitor titer }>10 \mathrm{BU} / \mathrm{mL}\end{array}$ & Factor VIII 25-50 IU/kg \\
\hline \multirow[t]{3}{*}{ FEIBA $100 \mathrm{U} / \mathrm{kg}$ BID } & $\begin{array}{l}\text { Cyclophosphamide } 12-15 \mathrm{mg} / \mathrm{kg} \text { IV daily } \times 2 \\
\text { days then } 2-3 \mathrm{mg} / \mathrm{kg} \text { PO daily } \times 8-10 \text { days }\end{array}$ & $\begin{array}{l}\text { BID for } 1-2 \text { weeks, then } \\
25 \mathrm{IU} / \mathrm{kg} \text { every other day }\end{array}$ \\
\hline & $\begin{array}{l}\text { FVIII is given to achieve a } 40 \%-100 \% \\
\text { fVIII level followed by fVIII infusion every } \\
8-12 \text { hours to achieve } 30 \%-80 \% \text { level }\end{array}$ & \\
\hline & $\begin{array}{l}\text { IVIG } 2.5-5 \mathrm{~g} \text { IV immediately after the first } \\
\text { fVIII infusion followed by } 0.4 \mathrm{~g} / \mathrm{kg} \text { daily } \\
\text { days } 4-8\end{array}$ & \\
\hline
\end{tabular}

Table-VII

Definitions of factor replacement therapy protocols for prophylaxis ${ }^{4,5,6}$

\section{Continuous prophylaxis}

Primary prophylaxis: Regular continuous treatment initiated in the absence of documented osteochondral joint disease, determined by physical examination and/or imaging studies, and started before the second clinically evident large joint bleed and age 3 years.

Secondary prophylaxis: Regular continuous treatment started after 2 or more bleeds into large joints and before the onset of joint disease.

Tertiary prophylaxis: $\quad$ Regular continuous treatment started after the onset of joint disease.

\section{Intermittent (periodic) prophylaxis}

Treatment given to prevent bleeding for periods not exceeding 45 weeks in a year..

Table-VIII

Prophylaxis regimen in hemophilia 5 .

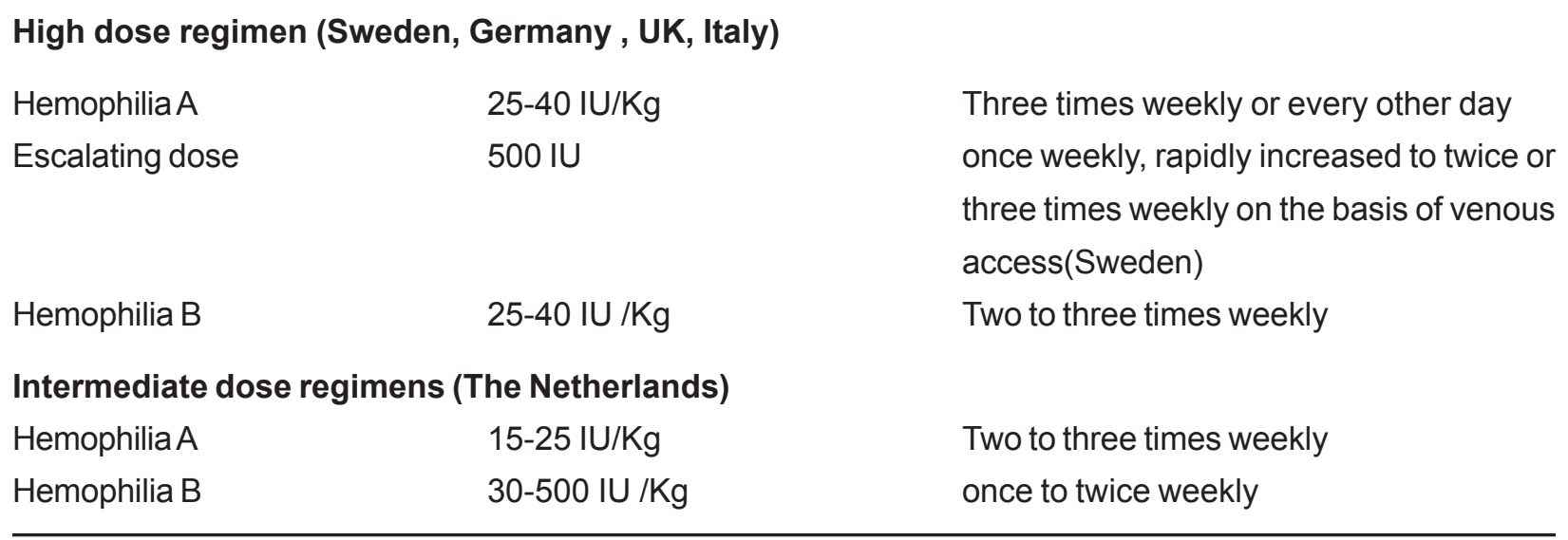




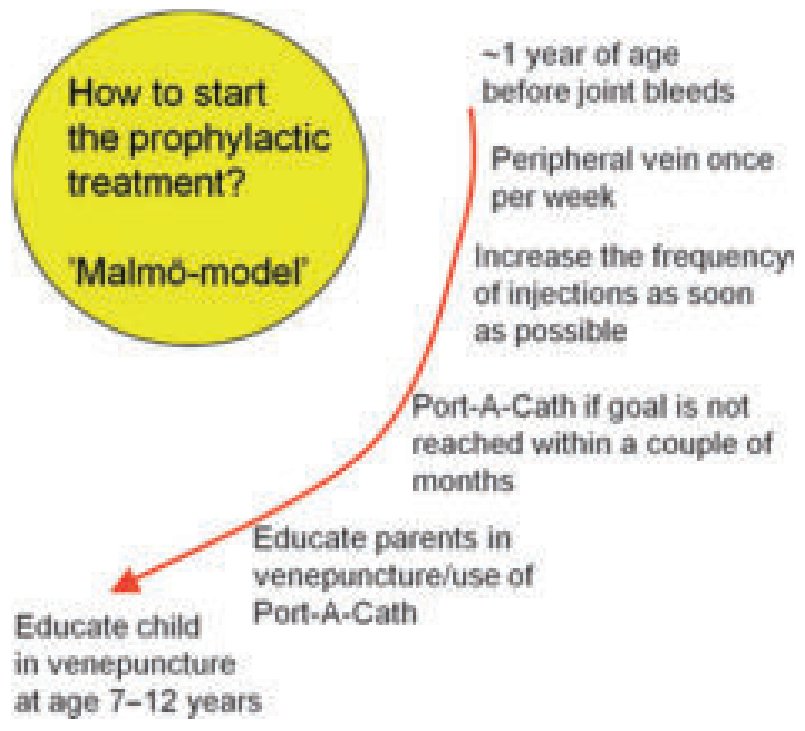

Fig. 2: Starting primary prophylaxis in patients with haemophilia. Model currently used in Malmo"

Although the cost of prophylaxis is very high, cost benefit study showed that the ultimate expenses may not be greater than those for treatment on demand. However, universal implementation of primary prophylaxis in children is challenging in developing countries where only resource for minimal on demand treatment is available 2 .

\section{Comprehensive care:}

Hemophilia care does not consist only of replacement therapy nd hematologic follow-up. The hematologist's clinical and laboratory expertise should be conjugated to other diagnostic and therapeutic facilities for the management of bleeding at various sites, surgery, and chronic complications. The need for a multidisciplinary integrated approach at specialized centers for this rare congenital disease requiring complex management has been recognized since the 1960s. Comprehensive care of hemophilic patients addresses treatment and prevention of bleeding, longterm management of hemophilic arthropathy and other complications of bleeding, management of significant complications of treatment Therefore, the core team at a hemophilia

comprehensive treatment center (HCTC), including hematologists, laboratory staff, nurses, physiotherapists and social workers, should involve the collaboration of several specialists. It should also involve the collaboration of several other allied specialists. Genetic counseling for patients and their families, and advice about prenatal diagnosis and management of pregnancy and delivery in hemophilia carriers should be offered (Coppola). Comprehensive care model has normalized life for patients with hemophilia in countries of the developed world with a life expectancy is close to healthy persons without the treat of transmission of serious blood-borne infections by concentrates since 1990, and joint disease produced by bleeding episodes is nonexistent in any normal population. Most centers practicing this model of care are based in developed countries and can meet costs for plentiful treatment products through government or insurance-company funding. Unfortunately,hemophiliacs in developing countries are far away to entertain these facilities, where major problems remains regarding diagnosis and treatment .

\section{Gene therapy:}

Through the introduction of a functional gene into a target cell, gene therapy aims to restore, modify or enhance cellular functions. Hemophiliacs are monogenic disorder and were felt an ideal target for gene therapy because only a small rise in factor concentrations to more than $1-2 \%$ of normal would achieve the goals of prophylaxis without regular infusions of concentrate and would ensure a substantial improvement in lifestyle for severe hemophilia ${ }^{5}$. The ultimate target of gene therapy for hemophiliacs A and B would be direct correction of the molecular defect in the mutated gene.

\section{Management of hemophilia in developing countries:}

It is estimated that $80 \%$ patients live in developing country and nearly $70 \%$ of the hemophiliacs are under diagnosed and remained untreated 10 . In contrast to the developing countries, where life expectancy of the hemophiliacs is close to normal healthy persons due to improved care and access to the clotting factors, most of the hemophiliacs in developing countries are still facing problem related to uncontrolled bleeds, hemarthroses and poor quality of life ${ }^{8,24}$.

Management of hemophilia in developing countries poses great challenges. Government and family monetary resources are usually inadequate, knowledge and awareness about hemophilia and its management often nonexistent, with often no access to proper diagnostic testing, and therapeutic material 
is inadequate not only in quantity but in terms of its viral safety. In addition, there are variations in populations with regard to income, education, and motivation levels. It is estimated that less than $5 \%$ of the population in developing countries would be able to provide a level of treatment for a hemophiliac son like that available in developed countries. Hemophilia care in developing countries targets with - a. Establishing regional HTCs at suitable place in the country with a goal to provide comprehensive care and making liaison with WFH, b. Capacity building with trained manpower and diagnostic facilities by making regional cooperation with established centers nearby, c. Making provision of adequate supply of factors replacement primarily by using available resources like FFP, cryoprecipitate by strengthening transfusion services and procurement of costly factors depending upon the available fund and encouragement for using of adjuvant modalities of treatment, d. Build up national hemophilia registry for actual identification of the hemophiliacs and e. Awareness about hemophilia and carrier detection with an aim for prevention hemophilia ${ }^{18}$.

Bangladesh perspectives: National registry for hemophilia of Bangladesh yet to be developed hence unavailability of reliable data regarding various parameters of the disease. Hemophiliacs are still taken care of by the general physicians and got special care in a handful number of specialized center mostly in the tertiary care hospitals in the capital city. Patients are usually diagnosed only after bleeding episode and some times the episode are serious causing serious consequences. Study on hemophilia is also scarce. Hospital based studies did not report any case detected in newborn period reflecting inadequacy of knowledge and attitude of the treating physician towards hemophilia ${ }^{25}$.

Like many other developing countries, Bangladesh is also lacking in comprehensive care for hemophiliacs. As per report of the annual global survey 2014 by WFH, only three hemophilia treatment centers are existing in Bangladesh ${ }^{9}$. However these centers are not well equipped with diagnostic facilities and adequate trained manpower. Under detection of the hemophiliacs: As there is no geographic, ethnic or racial variation in the incidence of hemophilia, given the prevalence of hemophilia A of 105 per million and of hemophilia B of 28 per million, Bangladesh (population 160 millions) would have 10800 hemophiliacs. But reported cases are only 657 (564 Hemophilia A and 93 hemophilia B) and there is no reported inhibitors. Among the reported cases, only 9 cases are under 5 years of age ${ }^{4}$.

Coagulation factors are not widely available throughout the country and throughout the year. No provision of supply of factors by the government. Only some private pharmacies mainly in the capital city procure by themselves and are selling with high prices. Alternative for factor like fresh frozen plasma, cryoprecipitate are available in a few old government medical college hospitals on demand. Hopefully blood bank facilities are expanding through out the country in government medical college hospitals and these alternative products could be ensured in near future for the poor fellows of hemophilia who can not procure costly factors.

Trained manpower: Shortage of expert and trained manpower for caring hemophilia is also another issue in our country. Good news is that Department of Pediatric Hematology and Oncology has been expanded in eight Medical Colleges with pediatric hematology specialist, where care of regional hemophiliacs might be arranged in near future. Bangladesh Hemophilia society, Hematology society of Bangldesh and Society of Pediatric Hematology of Bangladessh are working for betterment of hemophiliacs.

The role of World Federation of Hemophilia in the management of hemophilia:

The World Federation of Hemophilia (WFH) is a global not-for-profit organization devoted to care of hemophilia and related disorders. It started its journey Founded in 1963 in Montréal. Over the last 52 years; it has grown tremendously and now has 107 National Member Organizations and has been recognized by the World Health Organization. The WFH is working with the mission of to introduce, improve, and maintain care for patients with hemophilia and related disorders. The WFH organizes regular educational workshops on key aspects of hemophilia care. It offers fellowship to approximately 30 healthcare professionals each year that provide funding for a period of study of up to 8 weeks at an International Hemophilia Training Center of their choice. The WFH runs twinning program to help emerging hemophilia treatment centers to develop partnerships with wellestablished centers. As the ultimate goal of the WFH 
is to promote sustainable hemophilia treatment in developing countries, donations of concentrate are regularly made through the Humanitarian Aid program. WFH also publishes several useful publications, such as the WFH register of coagulation factor on management of hemophilia, Report of the annual global surveys on a regular basis ${ }^{25}$.

\section{Future prospects:}

Recombinant DNA technology and protein engineering are creating hope. Technological advances to improve the half-life of recombinant clotting factors for hemophilia replacement therapy is closer to reality. Other major aspects of research and development in pipeline toward the new therapeutic agents for hemophilia are: (1) lower cost factor concentrates, (2) non-protein therapies, (2) novel bypassing agents for hemostatic control of inhibitors. ${ }^{20,25}$.

\section{Conclusion:}

Hemophilia A (deficiency in factor [F] VIII) and hemophilia B (deficiency in FIX) are the most common serious congenital coagulation factor deficiencies. Vast majority of hemophiliacs, living in developing countries with poor to nonexistent services of hemophilia care, are facing the problem of bleeding along with its complications and poor quality of life. WFH with its mission and vision is trying to minimize the gap through expanding its different program. However successful management of the hemophiliacs in developing countries will largely depend primarily on the attitude of the participating countries. With the success of gene therapy and availability of the new bioengineered products the prospect of the hemophiliacs will be brighter in near future.

\section{References}

1. Berntrop E et al. Management of bleeding disorders in children Haemophilia 2012; 18 : 1523

2. Zimmerman B, Leonard A. Valentino. Hemophilia in Review. Pediatrics in Review 2013; 34; 289

3. Shaha MM, Ullah SMJ, Mondol DK, Bakar MA, Bhuiya JH, Hemophilia: An Update. J Bangladesh Coll Phys Surg 2007; 25:29-37.

4. World Federation of Hemophilia Annual Global Survey 2014. Available at ww.wfh.org/2/docs/ Publications/2014_Global_Survey_Report.pdf. accessdate $17 / 03 / 2016$
5. Mannucci PM, Tuddenham EGD. The Hemophilias-from royal gene to gene therapy.N Eng J Med 2001; 344:1773-79.

6. Sharathkumar A, Pipe S. Bleeding Disorders. Pediatrics in Review. 2008;29(4):121-30

7. Kulkarni R, Soucie JM.Pediatric Hemophilia: A Review. Semin Throm Hemost2011;37:737-44

8. Manony BO, Black C. Expanding hemophilia care in developing countries. Semin Throm Hemost 2005;31:561-68

9. Karim MA, Jamal CY. A Review on Hemophilia in Children. BangladeshJ Child Health 2013; VOL 37 (1) : 27-40

10. Antonio Coppolaet al. Treatment of hemophilia: a review of current advances and ongoing issues. Journal of Blood Medicine 2010:1 183-195

11. Lanzkowsky P. Hemostatic disorders. In: manual of Pediatric Hematology and Oncology, $5^{\text {th }}$ edition, Elsevier, 2011. 378-418

12. Kenet G, Chan AKC, Souchi JM, Kulnarni R. Bleeding Disorders in Neonates. Haemophilia. 2010; 16:168-74

13. Stieltjes N, Calvez T, Demiguel V, Claeyssens S, Coatmelec B, Chambost $\mathrm{H}$ et al. French $\mathrm{ICH}$ Study Group. Intracranial haemorrhages in French haemophilia patients (1991-2001): clinical presentation, management and prognosis factors for death. Haemophilia 2005; 11: 452-58.

14. Bell B, Canty D, Audet M. Hemophilia: An updated review. Pediatrics in Review1995;16: 290-98

15. Kim $\mathrm{KY}$, Yang $\mathrm{CH}$, Cho $\mathrm{MJ}$, Lee $\mathrm{M}$. Comprehensive clinical and statistical analysis of hemophilia in Korea 1988. J Korean Med Sc; 3:107-14.

16. Beyer R, Ingerslev J, Sorensen B. Current practice in the management of muscle hematomasi patients with severe hemophilia. Haemophilia 2010; 16: 926-31

17 Revel-Vilk S. Clinical and laboratory assessment of bleeding pediatric patients. Semin Throm Hemost. 2011; 37: 756-62.

18. Srivastava A, Brewer AK, Mauser-Bunschoten EP, Keys NS, KItchen S, Llinas A, Ludlam CA et al. WFH guidelines for the managemant of hemophilia. Haemophilia 2013:e1-e47 
19 Bell B, Canty D, Audet M. Hemophilia: An updated review. Pediatrics in Review1995;16: 290-98

20. Coppola A, Capua MD, Dario MN, Minno D, Di Palo $M$, Marrone $E$ et al. review of current advances and ongoing issues. $\mathrm{J}$ Blood Med 2010; 1:183-95.

21. Kruse-Jarres R. Inhibitos : Our greatest challenge. Can we minimize the incidence? Haemophilia 2013; 19(supp 1): 2-7.

22. Nelson MD Jr, Maeder MA, Usner D, Mitchell WG, Fenstermacher MJ, Wilson DA, et al.
Prevalenc Haemophilia Growth and Development Study. Haemophilia1999; 5: 306-12

23. Verbruggen $B$, van Heerde WL, Laros-van GorkomBA. Improvements in factor VIII inhibitor detection:from Bethesda to Nijmegen. Semin Thromb Hemost 2009;35(8): 752-59

24. Chandy M. Management of hemophilia in developing countries with available resources. Haemophilia 1995; 1(1): 44-8

25. Pipe SW. The hope and reality of long acting hemophilia products. Am J Hematol 2012;87: 33-39. 